\title{
Characterization of Monoclonal Antibodies against Heavy and Light Chains of Flounder (Paralichthys olivaceus) Immunoglobulin
}

\author{
Han-Na Jang ${ }^{\dagger}$, Jong-Kyu Woo ${ }^{\dagger}$, Young-Hye Cho, Seo-Bong Kyong and Sang-Hoon Choi* \\ Department of Marine Biomedical Science, Kunsan National University, Kunsan 573-400, Korea
}

Received 2 May 2003, Accepted 29 August 2003

\begin{abstract}
Flounder (Paralichthys olivaceus) Immunoglobulins (Igs) were purified from the serum of mouse IgG-immunized flounder by using affinity chromatography. Under denaturing conditions in SDS-PAGE, the flounder Igs appeared to be composed of 2 heavy $(\mathrm{H})$ chains $(72$ and 77 kDa) and two light (L) chains (26 and $28 \mathrm{kDa})$. Monoclonal antibodies (MAbs) were produced by the fusion of myeloma cells (SP2/0) with Balb/c mouse spleen cells that were previously sensitized against affinity-purified flounder Igs. In a Western blot analysis, the produced MAbs, FIM511, FIM519, and FIM562 recognized both the 72 and $77 \mathrm{kDa} H$ chains, $26 \mathrm{kDa}$, and $28 \mathrm{kDa} \mathrm{L}$ chain, respectively. Mouse antiserum against flounder Igs reacted more strongly with the $\mathrm{L}$ chain of $28 \mathrm{kDa}$ than with $26 \mathrm{kDa}$, suggesting that the $28 \mathrm{kDa}$ molecule is more immunogenic than the $26 \mathrm{kDa} \mathrm{L}$ chain molecule. In a FACS analysis, the ratios of the Ig+ cell population in the flounder head kidney and spleen cells were $49 \%$ and $24 \%$, respectively. Unexpectedly, however, the ratios of the Ig+ B-like cell population in the flounder were not significantly augmented, even after the immunization of an immunogenic antigen. This suggests that the humoral immune response in fish could be considerably different from that in mammals. The produced MAbs in this study would be useful in characterizing flounder Ig+ B-like cells and in developing flounder Ig detecting an immunoassay system.
\end{abstract}

Keywords: Immunoglobulin, FACS, Flounder, Monoclonal antibody

Present address: Dept. of Molecular, Cellular, and Developmental Biology, University of Colorado at Boulder, USA

*To whom correspondence should be addressed. Tel: 82-63-469-1886; Fax: 82-63-463-9493

E-mail: shchoi@kunsan.ac.kr

\section{Introduction}

Teleost fish possess both humoral and cell-mediated immunity (Graham and Secombes, 1990). Humoral immunity in the fish immune response involves the secretion of specific immunoglobulins (Igs) that are directed to neutralize antigens and activate the complement cascade (Rijkers, 1982). Two different Igs, IgM and the recently discovered $\operatorname{IgD}$ homologue, have been described in teleosts (Miller et al., 1998; Hordvik et al., 1999). Teleost IgM is similar to mammalian IgM in that both are composed of equimolar amounts of heavy $(\mathrm{H})$ chains $(70$ to $81 \mathrm{kDa})$ and light $(\mathrm{L})$ chains (22 to $32 \mathrm{kDa}$ ) (Wilson and Warr, 1992). In teleost $\mathrm{IgM}$, the disulfide bonding between adjacent $\mathrm{H}$ chains is not uniform and the non-covalent bonding is a frequent feature of the association of subunits to form a complete tetramer (Lobb, 1985; Kaattari et al., 1988). It has been suggested that the possession of different polymerization forms is a mechanism by which teleosts generate antibody diversity (Kaattari et al., 1988).

Immunological parameters, such as total and specific plasma Ig levels as well as the number of B and plasma cells in different tissues, may be used to evaluate immunocompetence and associated disease resistance. Monoclonal antibodies (MAbs) that specifically react with Ig provide a useful tool for a proper determination of these immunological parameters. During the last decade, MAbs have been produced to Ig of a number of teleost species (DeLuca et al., 1983; Secombes et al., 1983; Thuvander et al., 1990; Navarro et al., 1993; Sanchez et al., 1993). Most of these antibodies recognize the heavy $(\mathrm{H})$ chain of $\mathrm{Ig}$, whereas a few were obtained against the light (L) chain (Lobb et al., 1984; Sanchez and Dominguez, 1991; van der Heijden et al., 1995). This has greatly contributed to an improved understanding of the architecture and functioning of the immune system of teleost fish in general and the corresponding species in particular. In the present work, MAbs against flounder (Paralichthys olivaceus) Ig were produced and characterized. Furthermore, the obtained MAbs were employed to detect the Ig-bearing 
cells of flounder in a FACS analysis. The MAbs against flounder Ig may be very useful in evaluating and developing effective vaccines for flounder that are reared in many countries, as well as to monitor the therapy course for the pathogen-infected flounder.

\section{Materials and Methods}

Chemicals Mouse IgG, Freund's complete and incomplete adjuvant (FCA and IFA), Tween-20, mouse IgG-Sepharose 4B beads, polyethylene glycol (PEG, M.W. 1,300-1,600 and 4,000), hypoxantine aminopterine thymidine (HAT), and a ISO kit for isotyping mouse Igs were purchased from Sigma (St. Louis, USA). Dulbecco's Modified Eagle Medium (DMEM) was obtained from Gibco BRL (Grand Island, USA). Alkaline phosphate-conjugated goat anti-mouse IgG (G(mIgG-AP) and fluorescein-isothiocyanateconjugated goat anti-mouse IgG (GomIgG-FITC) were purchased from Promega (Madison, USA).

Administration of antigen Matured flounders (weighing 800$1,000 \mathrm{~g}$ and $8 \mathrm{mo}$ of age) were purchased from a commercial flounder-breeding farm. A total of 9 flounders were kept in a 300-1 glass aquaria at $12-17^{\circ} \mathrm{C}$ that was supplied with well water. To produce the antibody, the flounders were intraperitoneally immunized with $200 \mu \mathrm{g}$ of the mouse $\mathrm{IgG}$ that was emulsified with FCA. After 3 wk, the booster injection with FIA was performed, followed by a final injection with phosphate-buffered saline (PBS) three weeks later. Peripheral blood $(7 \mathrm{ml})$ was collected by puncture of the caudal vein of the flounder with a syringe and allowed to clot overnight at $4^{\circ} \mathrm{C}$. The serum was obtained by centrifugation at 2,500 rpm for $8 \mathrm{~min}$. The sera were used to purify Igs.

Purification of flounder immunoglobulin (Ig) Flounder Igs were purified by using mouse IgG-Sepharose 4B column chromatography. One $\mathrm{ml}$ of mouse IgG-Sepharose 4B beads were added to a column and allowed to gradually pack by gravity. The beads were washed with PBS and the elution buffer $(0.1 \mathrm{M}$ glycine buffer, $\mathrm{pH}$ 11), followed by equilibration of the beads with PBS. One milliliter of mouse IgG-immunized flounder serum was applied to the mouse IgG-Sepharose 4B column. After $10 \mathrm{~min}$, the column was washed with PBS. The flounder anti-mouse IgG was eluted from the mouse IgG-Sepharose $4 \mathrm{~B}$ column by the elution buffer, and then concentrated to $1 \mathrm{ml}$ with PEG (MW 4000). The fraction was dialyzed with PBS $(1,000 \mathrm{ml})$ for $24 \mathrm{~h}$ at $4^{\circ} \mathrm{C}$. The purity was checked by SDS-PAGE.

Production of MAbs Twelve-wk-old Balb/c mice were each immunized intraperitoneally with the purified flounder Igs $(200 \mu \mathrm{g})$ that were emulsified with FCA (Lee et al., 2001). Following 4 wk of immunization, a boosting was done with FIA. For a positive control, the mouse anti-flounder serum was collected through an eye bleeding on the day of fusion. Fusion was performed on day 4 after the second immunization. The mouse spleen cell suspension was prepared by rubbing the spleen with two slide glasses in serumfree DMEM. The myeloma cells (SP2/0), cultured in $10 \%$ fetal bovine serum-DMEM (10\% FBS-DMEM), were harvested and

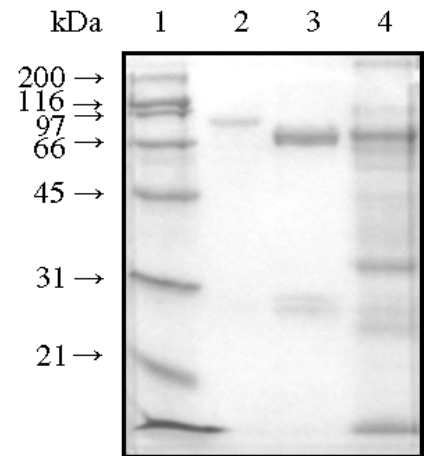

Fig. 1. SDS-PAGE for purified flounder Ig. Flounder Igs were purified by using mIgG-Sepharose 4B affinity column chromatography followed by SDS-PAGE. Lane 1, prestained standard marker; lane 2, purified carp Ig; lane 3, purified flounder Ig; lane 4, normal flounder serum.

washed twice with serum-free DMEM. Viability of the mouse spleen cells and myeloma cells was checked by the tryphan blue exclusion method.

Hybridomas were produced by the fusion method using PEG. Briefly, $1 \times 10^{8}$ of the spleen cells and $1 \times 10^{7}$ of the myeloma cells were mixed in a $50 \mathrm{ml}$ conical tube (Corning, Acton, USA), and the medium was removed by centrifugation. One $\mathrm{ml}$ of 50\% PEG (MW 1,300-1,600) was added to the cell pellet by dropping within $1 \mathrm{~min}$ at room temperature. The fused cells were washed twice with $20 \mathrm{ml}$ of the serum free-DMEM, followed by the addition of $21 \mathrm{ml}$ of HAT-media (15\% FBS-DMEM supplemented with 2\% (v/v) HAT supplement). The fused cells were cultured in 96-well plates (Corning) with mouse peritoneal macrophage as the feeder cells. To identify the antibody production against flounder Igs, hybridoma supernatants were screened by an enzyme-linked immunosorbent assay (ELISA). The hybridoma clones that produced the antibodies were established by limiting-dilution methods. The established hybridomas were stored in a liquid nitrogen tank and the supernatants were used for subsequent experiments (Fig. 1). Isotyping for MAbs was performed using a commercial kit, ISO-1.

Screening of MAbs The supernatant of the hybridoma cell culture was tested for the production of anti-flounder Igs by an enzyme-linked immunosorbant assay (ELISA). The precipitated normal flounder serum was diluted to $10 \mu \mathrm{g} / \mathrm{ml}$ in the coating buffer (15 mM sodium carbonate, $34 \mathrm{mM}$ sodium bicarbonate, $0.02 \%$ sodium azid). Each $50 \mu \mathrm{l}$ of the antigen (precipitated normal flounder serum) was dispensed to each well of a immuno module (Nunc). The plates were incubated for $30 \mathrm{~min}$ at $37^{\circ} \mathrm{C}$. The wells were washed three times with PBS, $\mathrm{pH} 7.4$, supplemented with $0.1 \%$ Tween-20 (T-PBS), and blocked for $1 \mathrm{~h}$ at $37^{\circ} \mathrm{C}$ with $50 \mu \mathrm{l}$ of $5 \%$ (weight/volume, w/v) skimmed milk in T-PBS to prevent nonspecific protein binding. The plate was washed and incubated again for $30 \mathrm{~min}$ at room temperature with $50 \mu \mathrm{l}$ of hybridoma supernatants. After removing the unresponded supernatants, GomIgG-AP was treated as a probe. All of the plates were washed three times after each step, except the substrate incubation. After the incubation for $30 \mathrm{~min}$ at room temperature, the plate was washed five times. The color reaction was initiated by adding 
$100 \mu \mathrm{l}$ of the substrate solution (BCIP/NBT in substrate buffer) to each well. The absorbance (Abs. 450) was read at $450 \mathrm{~nm}$ with a DigiScan ELISA Reader.

Immunoblot analysis Following SDS-PAGE, an immunoblot analysis was performed according to the slightly modified methods of Yi (Yi et al., 2001). Briefly, the samples (normal flounder serum, ammonium sulphate-precipitated normal flounder serum and mIgG-agarose-isolated Igs) were electrophoretically transferred $(100 \mathrm{~V}, 1 \mathrm{~h})$ onto a $0.45 \mu \mathrm{m}$ pore size polyvinylidene diflouride (PVDF) membrane (Millipore, Bedford, USA) using $20.8 \mathrm{mM}$ Tris, $160 \mathrm{mM}$ glycine and $16.67 \%(\mathrm{v} / \mathrm{v})$ methanol in distilled water as a running buffer. The membrane was blocked with 5\% skim milk in T-PBS for $1 \mathrm{~h}$ at room temperature, followed by a $1 \mathrm{~h}$-incubation with the hybridoma supernatants. The strips were then washed three times with T-PBS that was incubated for $1 \mathrm{~h}$ at room temperature with GomIgG-AP (1 : 5,000 in T-PBS), and washed five times for $5 \mathrm{~min}$ in T-PBS. For color development, the 5-bromo-4-chloro-3indolyl-phosphate (BCIP)/nitroblue tetrazolium (NBT) in the substrate buffer was added to blots for approximately $30 \mathrm{~min}$. The strips were then rinsed in distilled water and dried between sheets of Whatman filter paper. The color reaction was stopped by washing with distilled water. Mouse anti-flounder Igs were used as a positive control. Ten percent FBS-DMEM was used as a negative control.

Flow cytometry analysis To investigate the distribution of the surface Ig positive cell populations in the flounder kidney and spleen, mononuclear cells were obtained from the flounder's kidney and spleen. The mononuclear cells were washed twice with DMEM. The mononuclear cells were adjusted to $2 \times 10^{6}$ of cells in $100 \mu \mathrm{l}$ of DMEM, and then incubated with $100 \mu \mathrm{l}$ of the hybridoma supernatants for $30 \mathrm{~min}$ at $4^{\circ} \mathrm{C}$. After washing the cells that were bound with primary MAbs, $100 \mu \mathrm{l}$ of GomIgG-FITC was added, followed by incubation for $30 \mathrm{~min}$ at $4^{\circ} \mathrm{C}$. The cells were fixed by $200 \mu \mathrm{l}$ of PBS containing 2\% (w/v) paraformaldehyde. The fluorescence-positive cell populations were subsequently monitored on a flow cytometer (FACScan, Becton-Dickinson, Franklin Lakes, USA). Each of the $5 \times 10^{3}$ of cells per sample was collected for the FACS-analysis. Histograms for FL1 (FITC) were used to analyze the fluorescence-positive cell populations.

\section{Results}

\section{Production of MAbs to flounder Igs}

Preparation of antigen (flounder Igs) Sera from the flounder that was immunized with mouse $\mathrm{IgG}$ were pooled. The antibodies that were specific for mouse $\mathrm{IgG}$ were isolated on a mouse IgG-Sepharose 4B affinity column chromatography. The eluted proteins were analyzed on a denatured SDSPAGE. As shown in Fig. 1, the structure of the purified flounder Ig was observed to be composed of two H chains (72 and $77 \mathrm{kDa}$ ) and two L chains (26 and $28 \mathrm{kDa})$. The purified flounder Ig was used to immunize Balb/c for the production of MAbs against flounder Igs.
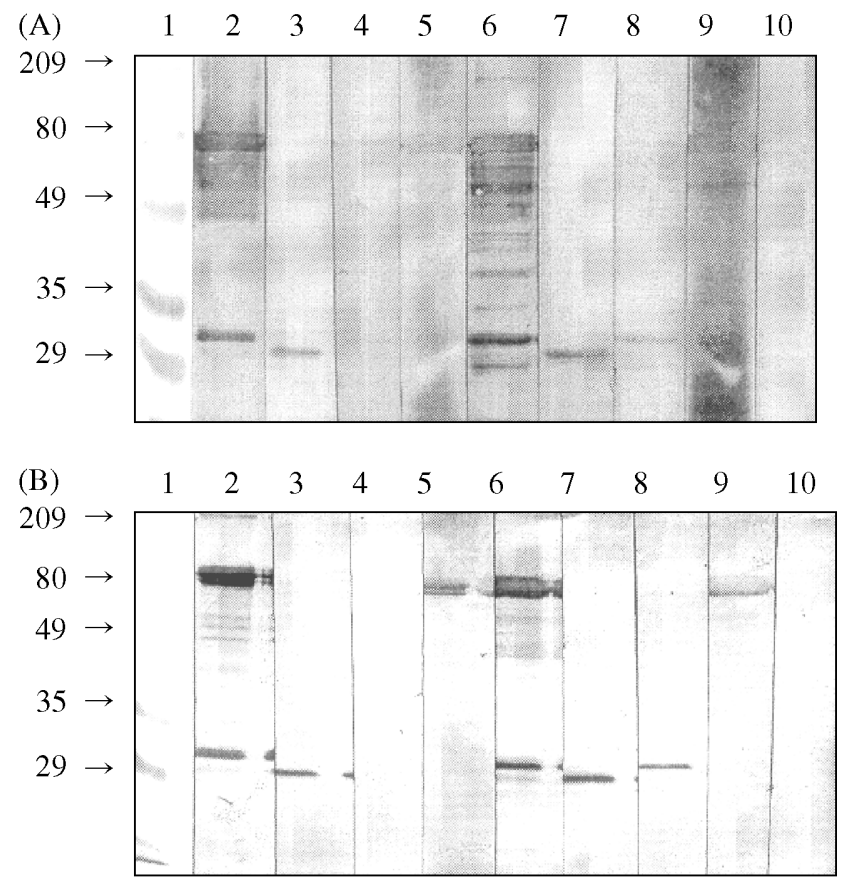

Fig. 2. Western blot analysis of flounder serum and Igs immunostained with MAbs, FIM 511, FIM519, and FIM562. Normal flounder serum, anti-flounder serum, and purified flounder Ig were electrophoresed, followed by an immunoblot analysis with flounder polyclonal antibodies and produced MAbs. A, immunoblot against normal flounder serum (lanes 2-5) and SAS-precipitated normal flounder serum (lanes 6-10); B, immunoblot against immunized flounder serum (lanes 2-5) and purified flounder Igs (lanes 6-10). Lane 1, standard marker; lanes 2 and 6, mouse polyclonal antibodies against flounder Ig; lanes 3 and 7, FIM519; lanes 4 and 8, FIM562; lanes 5 and 9, FIM511; lane 10, normal mouse serum (negative control).

Production of MAbs A total of 576 hybridoma clones (32\% of the total wells) were formed. An enzyme-linked immunosorbent assay (ELISA) screening was performed on the obtained fusion clones. Sixty (32\% of the total hybridoma clones) different clones appeared to positively react with the flounder Igs. Three MAbs were selected for further characterization and named FIM511, FIM519, and FIM562, respectively. The isotype classes of FIM511, FIM519, and FIM562 were IgG2, IgG1, and IgM, respectively.

Immunoblot analysis for MAbs Figure 2 shows the immunoblot analysis result of the produced MAbs that reacted with normal flounder serum, mouse IgG-immunized flounder serum, and the purified flounder Igs. In Fig. 2A, the normal flounder serum and SAS-precipitated samples were loaded on the gel, followed by immunoblotting with MAbs. The mouse antiserum against the affinity-purified flounder Igs was used as the positive control (lanes 2 and 6 in Figs. 2A and B). As shown in Fig. 2A, the positive control appeared to respond, not only to the $\mathrm{H}$ and $\mathrm{L}$ chains, but also to other serum 

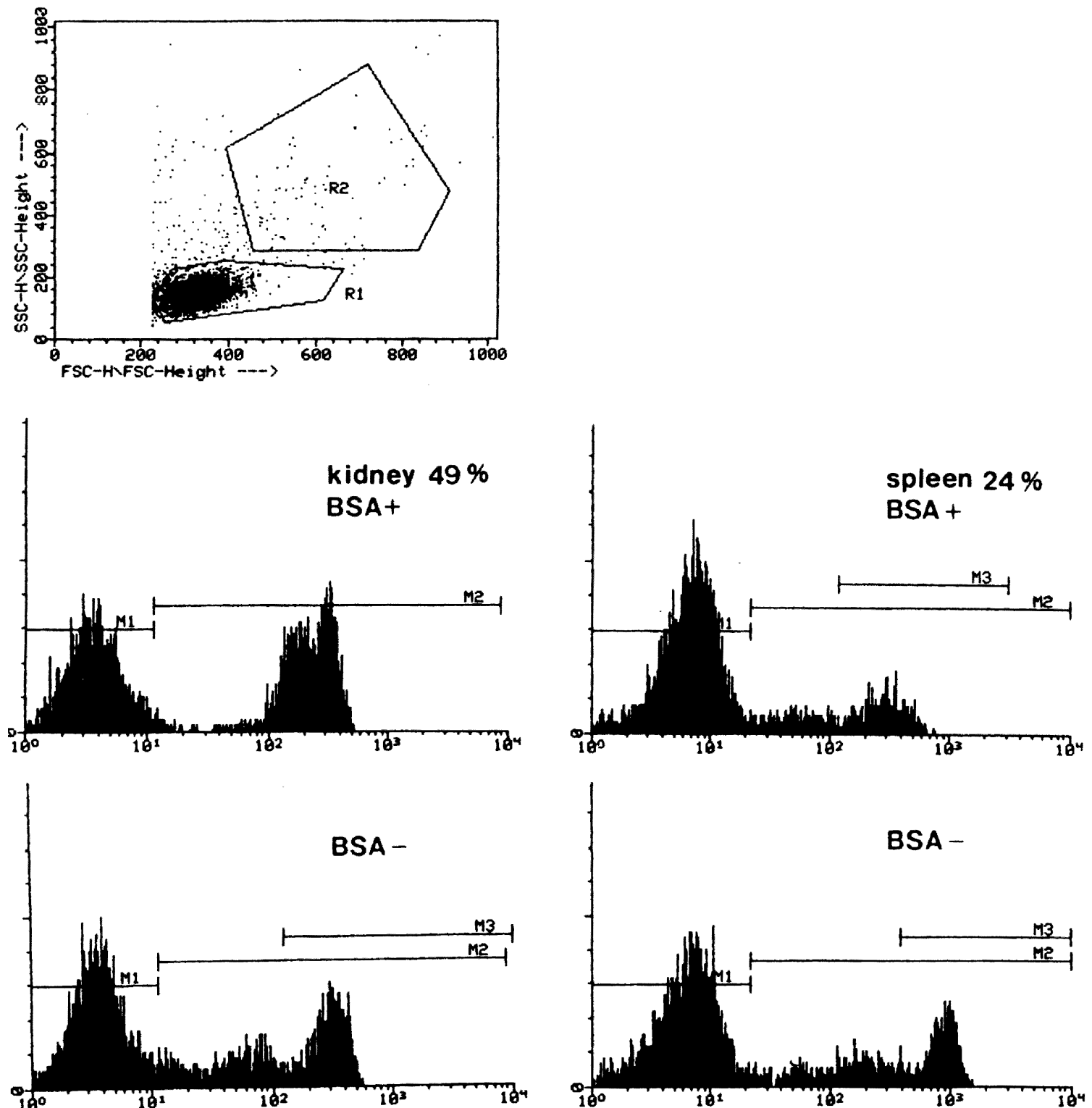

Fig. 3. Flow cytometric analysis of Ig+ B-like lymphoid cells in the head kidney and spleen from BSA- or non-immunized flounder. The cells $\left(5 \times 10^{5} / \mathrm{ml}\right)$ were incubated for $30 \mathrm{~min}$ on ice with saturating concentrations of FIM 511, followed by an incubation with fluorescein isothiocyanate conjugated goat anti-mouse IgG. A, FSC/SSC dot plot of head kidney cells showing the lymphoid cell gate (R1); B, flow cytometric histograms on both the head kidney and spleen cells from BSA- or non-immunized flounder.

was not completely pure. In Figs. 2A and B, FIM562 reacted with the $28 \mathrm{kDa} \mathrm{L}$ chains in the normal flounder serum, SASconcentrated normal flounder serum, and purified flounder Igs, but failed to respond to that in the anti-mouse $\operatorname{IgG}$ flounder serum.

FIM511, FIM519, and FIM562 reacted with the two $\mathrm{H}$ chains ( 72 and $77 \mathrm{kDa}$ ), one $\mathrm{L}$ chain $(26 \mathrm{kDa})$, and the other $\mathrm{L}$ chain $(28 \mathrm{kDa})$, respectively. In terms of band patterns (shown after MAbs reacted to various samples), there were no significant differences observed among the normal flounder serum, SAS-treated normal flounder serum, anti-flounder serum, and affinity-purified Igs.

Flow cytometry analysis To study whether the produced MAbs against flounder serum Igs recognize the surface Ig receptors that are present on flounder kidney or spleen cells, a FACScan analysis was performed using FIM511 MAb. Figure 3 shows the result of the flow cytometry analysis on the Ig+ cells in the kidney and spleen cells from BSA or nonimmunized flounder. The ratios of the $\mathrm{Ig}+$ cell population in the flounder kidney and spleen cells were revealed to be $49 \%$ and $24 \%$, respectively. 


\section{Discussion}

Specific antibodies (polyclonal and/or monoclonal) to immunoglobulins and their subunits are valuable tools in immunological research and immunological assays. It is generally accepted that the major serum IgM of teleosts has a tetrameric form with a $M_{r}$ between 600 and $900 \mathrm{kDa}$ (Wilson and Warr, 1992; Koumans-van Diepen et al., 1995; van der Heijden et al., 1995). However, dos Santos, et al. (1997) recently reported that the protein A-isolated sea bass (Dicentrarchus labrax L.) Ig appeared to have two H chains and at least one light chain, which suggest that the Ig structure in teleosts depends on fish species. Although, Romestand et al. (1995) and Palenzuela et al. (1996) reported the existence of only one $\mathrm{H}$ chain in sea bass, the present work clearly indicates the presence of at least two $\mathrm{H}$ chains. Palenzuela et al. (1996) also reported the existence of two L chains in sea bass IgM. The existence of more than one $\mathrm{H}$ and $\mathrm{L}$ chain is not new, since evidence of diversity in molecular weights structure and/or antigenicity in IgM of other teleost species have been reported (Koumans-van Diepen, 1995; van der Heijden, 1995; Palenzuela et al., 1996). The aim of this study was to produce MAbs against flounder serum Igs to develop an immunoassay system for the detection of flounder Igs, to further characterize the structure of flounder Ig, and to determine their usefulness in leukocyte scanning or sorting. To produce MAb against flounder Igs, Ig was purified from the $\mathrm{mIgG}$-immunized flounder serum by using mIgG-Sepharose 4B affinity chromatography.

The SDS-PAGE result showed that flounder Ig was composed of two $\mathrm{H}$ and $\mathrm{L}$ chains, whereas carp Ig was composed of a single $\mathrm{H}$ and $\mathrm{L}$ chain, as reported. MAb FIM 511 specifically recognized both $72 \mathrm{kDa}$ and $77 \mathrm{kDa}$ of the $\mathrm{H}$ chains and FIM 519 and FIM 562 recognized $26 \mathrm{kDa}$ and 28 $\mathrm{kDa}$ of the L chains, respectively. Specificity and titration of the produced MAbs were further confirmed with normal flounder serum, purified normal flounder Ig, and anti-flounder serum that was stimulated with antigen. In Fig. 2B, however, FIM562 failed to react with the $28 \mathrm{kDa} \mathrm{L}$ chain, suggesting a much lower amount of the $28 \mathrm{kDa} \mathrm{L}$ chain in the immunized serum than in the normal serum sample. Further study is being performed to ascertain the unexpected result. Bang et al. (1996) reported that flounder Ig that is induced by Edwardsiella tarda was composed of one type of the $\mathrm{H}$ chain and two types of the $\mathrm{L}$ chain. Their result, however, was somewhat different from ours in terms of the number of the $\mathrm{H}$ chain and the size of the $\mathrm{H}$ and $\mathrm{L}$ chains. To confirm these results, we performed the experiments several times with the same results. The possibility of different results might be explained by the utilization of different antigens to elicit the production of flounder Igs. Further study is required to clear up this discrepancy. Since FIM 511 recognized two $\mathrm{H}$ chains at the same time, we attempted to obtain other MAbs that are specific to each $\mathrm{H}$ chain, but we failed. Further studies should be performed to ascertain if the two $\mathrm{H}$ chains are constructed as a dimeric form in a single Ig molecule or if two different Igs with each different $\mathrm{H}$ chain isotype are present in the flounder serum.

In the FACS analysis, regardless of the antigen immunization, the ratios of the Ig+ B-like cell population in the flounder kidney and spleen cells appeared to $49 \%$ and $24 \%$, respectively. The result suggests two possibilities: (1) The flounder kidney might contain a larger number of Ig+ Blike cells than the flounder spleen. (2) The humoral immune response in fish could be considerably different than those of mammalians. Furthermore, the surface Ig receptors on the Blike cells in the kidney and spleen are likely to be the same as the serological Ig in the structural properties. Although extremely high percentages of Ig+ B-like cells were found in some tested fish, the individual variation among the five fish in a group could not be excluded. However, the relative ratios of the B-like cell population between flounder kidney and spleen were almost similar to the representative data that is presented here. In conclusion, the affinity-purified flounder Ig was composed of $2 \mathrm{H}$ and L chains, and the produced MAbs were specific for flounder Ig. The development of an effective antibody assay system might be a useful tool in diagnosing the various diseases that occur in fish, and in evaluating the efficacy of fish vaccines by measuring the exact amount of fish Igs.

Acknowledgment This work was supported by a Korea Research Foundation Grant (KRF-2000-015-HP0001).

\section{References}

Bang, J. D., Kim, J. W., Lee, S. D. Park, S. I. Chun, S. G. Jeong C. S. and Park. J. W. (1996) Humoral immune response of flounder to Edwardsiella tarda: the presence of various sizes of immunoglobulins in flounder. Dis. quat. Organ. 26, 197-203.

De Luca, D., Wilson, M. and Warr, G. W. (1983) Lymphocyte heterogeneity in the trout, Salmo gairdneri, defined with monoclonal antibodies to IgM. Eur. J. Immunol. 13, 546-551.

dos Santos, Taverne, N. M. S., Taverne-Thiele, N., de Sousa, A. J. and Rombout, H. W. M. (1997) Characterization of monoclonal antibodies specific for sea bass (Dicentrarchus labrax L.) IgM indicates the existence of B cell subpopulations. Fish Shellfish Immunol. 7, 175-191.

Graham, S. and Secombes, C. J. (1990) Cellular requirements for lymphocytes secretion by rainbow trout Salmo gairdneri leucocytes. Dev. Comp. Immunol. 14, 59-68.

Hordvik, I., Thevarjan, J., Samdal, I., Bastani, N. and Krossoy, B. (1999) Molecular cloning and phylogenetic analysis of the Atlantic salmon immunoglobulin D gene. Scand. J. Immunol. 50, 202-210.

Kaattari, S. L., Evans, D. A. and Klemer, J. V. (1988) Varied redox forms of teleost IgG: an alternative to isotypic diversity? Immunol. Rev. 166, 133-142.

Koumans-van Diepen, J. C. E., Egberts, E., Peixoto, B. R., Taverne, N. and Rombout, J. H. W. (1995) B cell and immunoglobulin heterogeneity in carp (Cyprinus carpio L.); an 
immuno (cyto) chemical study. Dev. Comp. Immunol. 19, 97108.

Lee, Y. S., Lee, G. T. and Cho, Y. D. (2001) Regulation of glyine max ornithine decarboxylase by salt and spermine. J. Biochem. Mol. Biol. 34, 478-483

Lobb, C. J. (1985) Covalent structure and affinity of channel catfish anti-dinitrophenyl antibodies. Mol. Immunol. 22, 993999.

Lobb, C. J., Olson, M. O. J. and Clem, L. W. (1984) Immunoglobulin light chain classes in a teleost fish. $J$. Immunol. 132, 1917-1923.

Miller, N., Wilson, M., Bengten, E., Stuge, T., Warr, G. and Clem, W. (1998) Functional and molecular characterization of teleost leucocytes. Immunol. Rev. 166, 187-197.

Navaro, V., Quesada, J. A., Abad, M. E and Rombout. J. H. W. M. (1993) Immuno (cyto) chemical characterization of monoclonal antibodies to Sparus aurata (Teleost) immunoglobulin. Fish Shellfish Immunol. 3, 167-177.

Palenzuela, O., Sitja-Bobadilla, A. and Alvarez-Pellitero, P. (1996) Isolation and partial characterization of serum immunoglobulins from sea bass (Dicentrarchus labrax L.) and gilthead sea bream (Sparus aurata L.). Fish Shellfish Immunol. 6, 81-94.

Rijkers, G. T. (1982) Kinetics of humoral and cellular immune reactions in fish. Dev. Comp. Immunol. Suppl. 2, 93-100.

Romestand, B., Breuil, G., Bourmaud, C. A. F., Coeurdacier, J. L. and Bouix, G. (1995) Development and characterization of monoclonal antibodies against sea bass immunoglobulins
Dicentrarchus labrax Linnaeus, 1758. Fish Shellfish Immunol. 5, 347-357.

Sanchez, C. and Dominguez, J. (1991) Trout immunoglobulin populations differing in light chains revealed by monoclonal antibodies. Mol. Immunol. 28, 1271-1277.

Sanchez, C., Lopez-Fierro, P., Zapata, A. and Dominguez, J. (1993) Characterization of monoclonal antibodies against heavy and light chains of trout immunoglobulins. Fish Shellfish Immunol. 3, 237-251.

Secombes, C. J., Van Groningen, J. J. M. and Egberts, E. (1983) Separation of lymphocyte subpopulations in carp Cyprinus carpio L. by monoclonal antibodies: Immunohistochemical studies. Immunology 48, 165-175.

Thuvander, A., Fossum, C. and Lorenzen, N. (1990) Monoclonal antibodies to salmonid immunoglobulin: characterization and applicability in immunoassays. Dev. Comp. Immunol. 14, 415423.

van der Heijden, M. H. T., Rooijakkers, J. B. M. A., Boons, G. H. R., Rombout. J. H. W. M. and Boon, J. H. (1995) Production, characterization and applicability of monoclonal antibodies to European eel (Anguilla anguilla L., 1758) immunoglobulin. Vet. Immunol. Immunopath. 45, 151-164.

Wilson, M. R. and Warr, G. W. (1992) Fish immunoglobulins and the genes that encode them. Ann. Rev. Fish Dis. 2, 201-221.

Yi, J. Y., Hong, W. S. and Son, Y. S. (2001) Biochemical characterization of adriamycin-resistance in PC-14 human lung adenocarcinoma cell line. J. Biochem. Mol. Biol. 26, 192-197. 